\title{
CLINICO-BIOCHEMICAL PROFILE OF HYPOTHYROIDISM IN RHEUMATOID ARTHRITIS
}

\author{
PREEMA KHAN*
}

Department of Internal Medicine, East Point College of Medical Sciences and Research Centre, Bengaluru, Karnataka, India Email: preema6khan@gmail.com

Received: 12 November 2021, Revised and Accepted: 20 December 2021

ABSTRACT

Objectives: The incidence of co-occurrence of multiple autoimmune diseases in a single patient is constantly increasing. Conditions with auto immune backgrounds such as rheumatoid arthritis and thyroid dysfunction have an immense relationship. This study was designed to evaluate the association biochemical parameters and disease progression in rheumatoid arthritis cases with hypothyroidism.

Methods: A total of 120 adult participants diagnosed with rheumatoid arthritis with suggestive hypothyroidism between 21 and 55 years of age were included in this study. All cases underwent complete laboratory investigations including thyroid profile. Depending on the diagnostic outcome of the thyroid profile, the participants were divided into two groups, that is, group 1 consists of rheumatoid arthritis with hypothyroidism and group 2 consists of rheumatoid arthritis without hypothyroidism.

Results: The higher mean values of FT3 and FT4 were observed in RA with hypothyroidism and mean levels of thyroid function test were statistically significant in between the study groups ( $\mathrm{p}<0.05$ ). The hypertriglyceridemia in $43.3 \%$ cases, hypercholesterolemia in $58.3 \%$, hyperuricemia in $26.6 \%$, and diabetes mellitus in $35 \%$ cases were commonly observed metabolic complications.

Conclusion: The higher levels of metabolic complications, namely, hypercholesterolemia, hyperuricemia, hypertriglyceridemia, and diabetes mellitus were noticed in rheumatoid arthritis with hypothyroidism. Regular screening of patients is recommended to monitor the status of the condition and to maintain a healthy lifestyle.

Keywords: Rheumatoid arthritis, Thyroid function test, Hypothyroidism.

(C) 2022 The Authors. Published by Innovare Academic Sciences Pvt Ltd. This is an open access article under the CC BY license (http://creativecommons.org/ licenses/by/4.0/) DOI: http://dx.doi.org/10.22159/ajpcr.2022v15i2.43579. Journal homepage: https://innovareacademics.in/journals/index.php/ajpcr

\section{INTRODUCTION}

Rheumatoid arthritis (RA) is a chronic autoimmune inflammatory condition that affects around $0.5-1 \%$ of the general population and is 3 times more common in women [1]. This idiopathic disease affects multiple tissues and organs but mainly affects the synovial joints. Malaise, fatigue, and morning stiffness are the characteristic symptoms of RA [2]. RA is associated with several autoimmune diseases including autoimmune thyroiditis which leads to hypothyroidism [3]. Thyroid dysfunction has an inverse relationship with rheumatoid arthritis. Moreover, this relationship is still an ongoing debate. The thyroid dysfunction was 3 times more common in women with RA than women with rheumatic conditions such as osteoarthritis and fibromyalgia [4].

Several studies have reported that thyroid dysfunction and RA are strongly associated, probably due to autoimmunity but could not justify. Few other studies assessed clinical characteristics and the impact of thyroid dysfunction on diseases activity [5]. This study was designed to evaluate the association biochemical parameters and disease progression in rheumatoid arthritis cases with hypothyroidism.

\section{METHODS}

A total of 120 adult participants diagnosed with rheumatoid arthritis with suggestive hypothyroidism were recruited for this cross-sectional study carried out in the Department of General Medicine at East Point college of Medical Sciences and Research Centre, Bangalore from January 2021 to December 2021.

\section{Inclusion criteria}

The diagnosis was made according to the American College of Rheumatology (ACR) criteria for rheumatoid arthritis [6]. According to the Dutch National Health-care Consensus Committee, the elevated level of TSH $>4.2 \mu \mathrm{IU} / \mathrm{ml}$ with lower than reference range of T3/T4 considered as hypothyroidism.

\section{Exclusion criteria}

Cases below 21 years and above 55 years of age, in pregnancy, history of thyroid surgery, and under medication for hypothyroidism were excluded from the study. After briefing the study procedure, written informed consent was obtained from all the study participants and Institutional Ethics Committee approval was obtained.

The patients attending the OPD of rheumatology with a history of thyroid complications and newly diagnosed with thyroid diseases were undergone thyroid function tests to evaluate TSH, FT3, and FT4 levels. Depending on the diagnostic outcome values, the participants were divided into two groups, that is, group 1 consists of rheumatoid arthritis with hypothyroidism and group 2 consists of rheumatoid arthritis without hypothyroidism. The parameters include serum lipid profile and LFT. RFT and their link to the disease progression and severity were assessed.

\section{Statistical analysis}

The recorded data were extracted into the Microsoft Excel sheet. The SPSS version 16.0 was used to carry out statistical analysis relevant to the study. The demographic and categorical variables were represented in the form of frequency and percentages. The continuous variables were represented in mean and standard deviation. The Student " $t$ " test was used to test the significant difference of mean. $p<0.05$ was considered statistically significant.

\section{RESULTS}

The mean age was $44.64 \pm 6.25$ in rheumatoid arthritis cases with hypothyroidism and $45.80 \pm 6.92$ in rheumatoid arthritis cases without 
hypothyroidism. The mean difference of age was statistically significant $(p<0.001)$. Female participants were dominant in both the study groups. The mean difference in waist circumference was statistically not significant $(\mathrm{p}=0.256)$ (Table 1$)$.

The mean levels of thyroid function test were statistically significant in between both the study groups $(\mathrm{p}<0.05)$ (Tables 2 and 3 ).

\section{DISCUSSION}

Rheumatoid arthritis is widely associated with various autoimmune diseases, autoimmune thyroiditis is important among, which resulting hypothyroidism [7]. The mean age was $44.64 \pm 6.25$ in group 1 and $45.80 \pm 6.92$ in group 2 and the difference was statistically significant $(\mathrm{p}<0.001)$. Hypothyroidism was observed more common in females than males [8-10]. The above findings were similar with the present study where female dominance was observed in RA with hypothyroidism (female 36 and male 24). A study by Haitham et al. reported a higher prevalence of hypothyroidism in females (76.66\%) [11]

The higher mean values of FT3 and FT4 were observed in RA with hypothyroidism. The mean levels of thyroid function test were statistically significant in both the study groups $(p<0.05)$. The FT3 $(\mathrm{p}<0.001)$, FT4 $(\mathrm{p}<0.001)$, and TSH $(\mathrm{p}<0.001)$ levels showed a significant difference in the RA cases with hypothyroidism. The higher levels and positive correlation TSH are associated with the higher grades of RA disease activity [8]. A study by Haitham et al. reported a positive correlation between TSH and ESR, which indicate higher disease activity when TSH levels were high [11]. A study by Israa M. Saqre et al. noticed higher T3 and T4 levels in female cases with RA. However, TSH levels were higher in males than females [12]

The common metabolic complications associated are hypertriglyceridemia in $43.3 \%$ cases, hypercholesterolemia in $58.3 \%$, hyperuricemia in $26.6 \%$, and diabetes mellitus in $35 \%$ cases (Table 4). The elevated level of cholesterol was observed in cases with hypertriglyceridemia which may be responsible for the triggering of cardiovascular complications and diminishing the eGFR. The group 1 cases with hypertriglyceridemia and diabetes may be reasons for the escalation of serum bilirubin and serum AST levels.

Hypercholesterolemia was the common metabolic complication noticed in $58.3 \%$ of cases which were associated with reduced ejection fraction, eGFR, and lung disease in $40 \%, 22.85 \%$, and $8.57 \%$ cases, respectively. Around $26.6 \%$ of cases reported hyperuricemia and associated with diminishing in eGFR in $43.75 \%$ of cases. Diabetes mellitus was noticed in $35 \%$ cases and associated with the lower levels of eGFR in $52.38 \%$.

The ESR levels were higher in RA cases with autoimmune thyroid disorders (AITD) than without AITD. A significant elevation in ESR levels is associated with RA cases with hypothyroidism [12]. Similar findings were observed with elevated ESR levels were observed in RA with hypothyroidism $(26.94 \pm 10.26)$. A study by Joshi et al. found elevated levels of ESR in cases with RA with hypothyroidism $(36.3 \pm 24.2)$ than only RA $(24.6 \pm 9.0)[13]$. The elevated ESR levels strengthen the role of hypothyroidism in the triggering of inflammatory mechanisms in rheumatoid arthritis. However, few studies reported no significant increase in the ESR with hypothyroidism in RA [11,14,15].

Anne et al. stated the prevalence of hypothyroidism more in cases with RA, especially among young women [2]. Enas et al. concluded that hypothyroidism was commonly associated with rheumatoid arthritis and has a significant association with the parameter triggering disease activity [8]. Haitham et al. and Nadeem et al. concluded that thyroid dysfunction commonly associated with RA and hypothyroidism is the most prevalent form among [11]. In the present study, the majority of cases in group 1 had vulnerable metabolic complications such as hypercholesterolemia, hyperuricemia, and diabetes mellitus. In addition, these metabolic complications are associated with renal
Table 1: Descriptive data of demographic variables in two study groups

\begin{tabular}{llll}
\hline Demographic variable & $\begin{array}{l}\text { Group 1 } \\
\text { (n=60) }\end{array}$ & $\begin{array}{l}\text { Group 2 } \\
\text { (n=60) }\end{array}$ & p-value \\
\hline Age (In years) & $44.64 \pm 6.25$ & $45.80 \pm 6.92$ & 0.001 \\
Gender (M: F) & $24: 36$ & $28: 32$ & - \\
Waist circumference & $78.63 \pm 6.55$ & $76.78 \pm 6.84$ & 0.256 \\
\hline
\end{tabular}

Table 2: Comparison of thyroid function test between two study groups

\begin{tabular}{llll}
\hline Thyroid parameters & Group 1 & Group 2 & p-value \\
\hline FT3 & $100.14 \pm 15.26$ & $136.28 \pm 24.30$ & 0.003 \\
FT4 & $6.28 \pm 2.32$ & $9.56 \pm 2.88$ & 0.002 \\
TSH & $2.84 \pm 2.52$ & $1.87 \pm 1.02$ & 0.026 \\
\hline
\end{tabular}

Table 3: Laboratory investigation profile between the two study groups

\begin{tabular}{|c|c|c|c|c|}
\hline \multirow[t]{2}{*}{ Parameters } & \multirow{2}{*}{$\frac{\text { Group } 1}{\text { Mean } \pm S D}$} & \multirow{2}{*}{$\frac{\text { Group } 2}{\text { Mean } \pm S D}$} & \multirow[t]{2}{*}{$\mathbf{F}$} & \multirow[t]{2}{*}{ p-value } \\
\hline & & & & \\
\hline FBS (mg/dl) & $119.23 \pm 39.98$ & $92.34 \pm 28.65$ & 11.45 & 0.002 \\
\hline PBS (mg/dl) & $168 \pm 26.24$ & $140 \pm 20.18$ & 19.64 & 0.002 \\
\hline HBA1C & $5.89 \pm 0.84$ & $5.69 \pm 0.64$ & 1.78 & 0.314 \\
\hline TGL (mg/dl) & $141.23 \pm 28.02$ & $104.44 \pm 30.58$ & 8.10 & 0.002 \\
\hline $\begin{array}{l}\text { Serum cholesterol } \\
(\mathrm{mg} / \mathrm{dl})\end{array}$ & $189.2 \pm 31.20$ & $163.48 \pm 28.94$ & 5.88 & 0.002 \\
\hline LDL (mg/dl) & $114.06 \pm 37.64$ & $96.22 \pm 35.45$ & 5.62 & 0.028 \\
\hline HDL (mg/dl) & $45.34 \pm 10.41$ & $48.67 \pm 8.82$ & 5.12 & 0.004 \\
\hline $\begin{array}{l}\text { Serum creatinine } \\
(\mathrm{mg} / \mathrm{dl})\end{array}$ & $1.02 \pm 0.24$ & $0.28 \pm 0.56$ & 1.48 & 0.075 \\
\hline Serum uric acid & $8.98 \pm 4.57$ & $6.32 \pm 2.35$ & 12.684 & 0.001 \\
\hline Serum bilirubin & $0.75 \pm 0.26$ & $0.76 \pm 0.53$ & 0.168 & 0.538 \\
\hline eGFR & $84.35 \pm 28.51$ & $92.38 \pm 30.18$ & 1.91 & 0.003 \\
\hline $\begin{array}{l}\text { Ejection fraction } \\
\text { value }\end{array}$ & $53.38 \pm 7.74$ & $57.20 \pm 7.28$ & 1.786 & 0.048 \\
\hline Hb levels & $10.99 \pm 3.62$ & $12.45 \pm 3.84$ & 1.538 & 0.074 \\
\hline ALT levels & $29.99 \pm 5.42$ & $29.36 \pm 5.08$ & 0.043 & 0.065 \\
\hline ESR & $26.94 \pm 10.26$ & $18.12 \pm 8.76$ & 8.612 & 0.004 \\
\hline
\end{tabular}

*FBS: Fasting blood sugar, PBS: Postprandial blood sugar, TGL: Triglycerides, LDL: Low density cholesterol, HDL: High density cholesterol, ESR: Erythrocyte sedimentation ratio. ${ }^{*} \mathrm{p}<0.05$ is statistically significant.

Table 4: Elevated levels of factors associated with development hypothyroidism $(n=60)$

\begin{tabular}{lll}
\hline Factors & Frequency & Percentage \\
\hline Hypertriglyceridemia & 26 & 43.3 \\
Hypercholesterolemia & 35 & 58.3 \\
Hyperuricemia & 16 & 26.6 \\
Diabetes mellitus & 21 & 35 \\
\hline
\end{tabular}

and cardiovascular complications which strengthen the role of hypothyroidism in triggering rheumatoid arthritis. Further studies are needed to evaluate the natural history of thyroid dysfunction in RA cases to formulate standardized duration between assessments of thyroid function.

\section{CONCLUSION}

The higher levels of metabolic complications, namely, hypercholesterolemia, hyperuricemia, hypertriglyceridemia, and diabetes mellitus were reported in rheumatoid arthritis with hypothyroidism than without hypothyroidism. Regular screening of patients is recommended to monitor the status of the condition and to maintain a healthy lifestyle. 


\section{AUTHOR CONTRIBUTION}

Conceptualization, data Acquisition, data analysis and interpretation, manuscript preparation, revision of manuscript, and approval of final version of manuscript: Dr. Preema Khan.

\section{AUTHOR FUNDING}

Nil.

\section{CONFLICT OF INTEREST}

Nil.

\section{REFERENCES}

1. Choy E. Understanding the dynamics: Pathways involved in the pathogenesis of rheumatoid arthritis. Rheumatology (Oxford) 2012;51 Supp1 5:v3-11.

2. Howard R, Kristine M, Francisco T, Elliot G, Alex JM, Herbert S. Rheumatoid Arthritis, eMedicine, Medical Disability Guidelines; 2006. Available from: https://www.mdguidelines.com/arthritisrheumat [Last accessed on 2006 May 24]

3. Anne MK, Nieminen T, Markku JK, Kautiainen H, Puolakka K, Lauri J. Virta. Increased Prevalence of Hypothyroidism Preceding Rheumatoid Arthritis-an Epidemiological Study, ACR/ARHP Annual Meeting Abstracts; 2012.

4. Shiroky J, Cohen M, Ballachey M, Neville C. Thyroid dysfunction in rheumatoid arthritis; a controlled prospective survey. Ann Rheum Dis 1993;52:454-6.

5. Pan XF, Gu JQ, Shan ZY. Increased risk of thyroid autoimmunity in rheumatoid arthritis: A systematic review and meta-analysis. Endocrine
2015;50:79-86.

6. Aletaha D, Neogi T, Silman AJ. Rheumatoid arthritis classification criteria: An American college of rheumatology/European league against rheumatism collaborative initiative. Arthritis Rheum 2010;62:2569-81.

7. Fukui S, Ikeda Y, Kataoka Y. Clinical significance of monitoring hypothyroidism in patients with autoimmune rheumatic disease: A retrospective cohort study. Sci Rep 2021;11:13851.

8. Enas AE, Younes TB, Mobasher SA. Hypothyroidism in patients with rheumatoid arthritis and its relation to disease activity. Egypt Rheumatol Rehabil 2014;41:58-65.

9. Raterman H, van Halm V, Voskuyl A, Simsek S, Dijkmans B, Nurmohamed M. Rheumatoid arthritis is associated with a high prevalence of hypothyroidism that amplifies its cardiovascular risk. Ann Rheum Dis 2008;67:229-32.

10. Chandankhede M, Gupta M, Chandankhede S, Chari S. Thyroid profile in female patients with rheumatoid arthritis. J Recent Adv Appl Sci 2011;26:34-6

11. Haitham AA, Alkabeer A, Alaa MH, Mohammed MR. Study of prevalence of hypothyroidism in rheumatoid arthritis patients and its impact on disease severity. Int J Clin Rheumatol 2019;14:151-9.

12. Israa MS, AS El-Bahnasawy, El-Dein MF, Fagr BB. Autoimmune thyroid disease in Egyptian patients with rheumatoid arthritis. Egypt Rheumatol 2019;41:167-71.

13. Joshi P, Agarwal A, Vyas S, Kumar R. Prevalence of hypothyroidism in rheumatoid arthritis and its correlation with disease activity. Trop Doct 2017:47:6-10.

14. Nadeem M, Khaliq A, Bhat MH, Mustafa F, Mushtaqe M. Spectrum of thyroid disorders in sero-positive rheumatoid arthritis. Thyroid Disord Ther 2017;6:225.

15. Amany AM, Mohamed G, Asmaa H, Azza AE, Amany E. Thyroid function and autoantibodies in Egyptian patients with systemic lupus erythematosus and rheumatoid arthritis. Trends Med Res 2012;7:25-33. 